\title{
BMJ Open Is acute idiopathic pericarditis associated with recent upper respiratory tract infection or gastroenteritis? A case-control study
}

\author{
Florian Rey, ${ }^{1,2}$ Cecile Delhumeau-Cartier, ${ }^{3}$ Philippe Meyer, ${ }^{1}$ Daniel Genne ${ }^{4}$
}

To cite: Rey F, DelhumeauCartier C, Meyer P, et al. Is acute idiopathic pericarditis associated with recent upper respiratory tract infection or gastroenteritis?

A case-control study. BMJ Open 2015;5:e009141. doi:10.1136/bmjopen-2015009141

- Prepublication history and additional material is available. To view please visit the journal (http://dx.doi.org/ 10.1136/bmjopen-2015009141).

Received 19 June 2015 Revised 13 October 2015 Accepted 15 October 2015

CrossMark

${ }^{1}$ Division of Cardiology, University Hospital of Geneva, Geneva, Switzerland ${ }^{2}$ Department of Internal Medicine, Neuchâtelois Hospital, La Chaux-de-Fonds, Switzerland

${ }^{3}$ University Hospital of Geneva, Geneva, Switzerland ${ }^{4}$ Department of Internal Medicine, Hospital Center of Bienne, Bienne, Switzerland

Correspondence to Dr Philippe Meyer; philippe.meyer@hcuge.ch

\section{ABSTRACT}

Objectives: The aim of this study was to assess the association of a clinical diagnosis of acute idiopathic pericarditis (AIP), and a reported upper respiratory tract infection (URTI) or gastroenteritis (GE) in the preceding month.

Design: Patients who were hospitalised with a first diagnosis of AIP were retrospectively compared with a control group of patients admitted with deep vein thrombosis (DVT), matched by gender and age.

Setting: Primary and secondary care level; one hospital serving a population of about 170000 .

Participants: A total of 51 patients with AIP were included, of whom 46 could be matched with 46 patients with control DVT. Only patients with a complete review of systems on the admission note were included in the study.

Main outcome measure: Conditional logistic regression was used to assess the association of a clinical diagnosis of AIP and an infectious episode (URTI or GE) in the month preceding AIP diagnosis.

Results: Patients with AIP had more often experienced a recent episode of URTI or GE than patients with DVT $(39.1 \%$ vs $10.9 \%, p=0.002)$. The multivariate conditional regression showed that AIP was independently associated with URTI or GE in the last month preceding diagnosis (OR=37.18, 95\% $\mathrm{Cl}=1.91$ to $724.98, \mathrm{p}=0.017$ ).

Conclusions: This is, to the best of our knowledge, the first study demonstrating an association between a recent episode of URTI or GE and a clinical diagnosis of AIP.

\section{INTRODUCTION}

Acute pericarditis refers to inflammation of the pericardial layers and possible increased production of pericardial fluid. ${ }^{1}$ It is encountered in about $0.1 \%$ of hospitalised patients and $5 \%$ of patients admitted to the emergency department for non-ischaemic chest pain. ${ }^{1}$ Acute pericarditis is considered to be the most common form of pericardial disease with at least $80 \%$ of all cases

\section{Strengths and limitations of this study}

- This is, to the best of our knowledge, the first study specifically examining the association between a diagnosis of acute idiopathic pericarditis and a recent preceding viral illness.

- The originality of this case-control study was in the use of detailed clinical information obtained via comprehensive admission notes in both groups, which reduced potential bias in the analysis.

- The relatively small sample size of the study ( $n=46$ in each group) is a limitation, even though the results were statistically significant.

- A prospective collection of data in cases and controls would have been more accurate compared to our retrospective design.

diagnosed as acute idiopathic pericarditis (AIP), which is supposed to be viral in most cases. ${ }^{1-3}$ Several viruses have indeed been identified in AIP with effusion even though microbiological investigations are not routinely performed in clinical practice. ${ }^{4}{ }^{5}$ Its diagnosis is based on four clinical criteria (pericarditic chest pain, pericardial rubs, new widespread ST-elevation or PR depression on ECG and new or worsening pericardial effusion) of which at least two are required. ${ }^{1}$ Prior studies have shown that typical chest pain was present in more than $95 \%$ of cases, while the other three criteria were more variable. ${ }^{367}$

According to current guidelines on pericardial disease, signs and symptoms of systemic infection such as fever or leucocytosis may be present in acute pericarditis. ${ }^{1}$ AIP is thought, by the medical community, to often be preceded by a recent upper respiratory tract infection (URTI) or gastroenteritis (GE), but this association has never been demonstrated. The aim of this study was to examine the association of a recent (last 
1-month period) episode of URTI or GE and the clinical diagnosis of AIP. This association might be helpful for physicians in the differential diagnosis of non-ischaemic chest pain in the emergency room.

\section{METHODS}

\section{Study design}

This was a case-control study where patients hospitalised with a diagnosis of AIP were compared with a control group of patients admitted with deep vein thrombosis (DVT). Patients of the two groups were matched by gender and age (age difference $\leq 3$ years). We retrospectively analysed data from November 2006 to November 2011 of all consecutive patients admitted for AIP and DVT at the Neuchâtelois Hospital (Switzerland), which serves a population of about 170000 . The main outcome was the association of a diagnosis of AIP or DVT with an infectious episode (URTI or GE) in the month preceding diagnosis. International Classification of Diseases (ICD) 10 codes of hospitalisation for AIP and DVT were extracted from the hospital electronic database. All demographic and medical data were retrieved from medical written records between November 2011 and July 2014.

Only patients admitted in internal medicine wards were selected. There is no cardiology department at the Neuchâtelois Hospital. However, patients with acute pericarditis who need to be hospitalised are admitted in internal medicine wards where cardiologists act as consultants.

All medical charts contained a comprehensive admission note with structured items concerning medical history and physical examination. Patients with admission notes containing a complete review of systems including an accurate description of pulmonary, digestive and systemic symptoms and their time of occurrence, were retained (see online supplementary appendices).

URTI was defined as an acute infection involving the nose, paranasal sinuses, pharynx and larynx. The prototype was the illness known as the common cold in addition to pharyngitis, sinusitis and tracheobronchitis. ${ }^{8}$ GE was defined as diarrhoeal disease ( $\geq 3$ liquid stools per day) of rapid onset that lasted $<2$ weeks and possibly accompanied by nausea, vomiting, fever or abdominal pain. ${ }^{9}$

In patients with AIP, several specific variables known as predictors of poor outcome ${ }^{6}$ were collected: number of pericarditis relapses (defined as a new episode of pericarditis occurring at least 6 weeks after the previous one), duration and nature of the treatment, presence of pericardial effusion or cardiac tamponade, failure of non-steroidal anti-inflammatory drug therapy, immunosuppression, oral anticoagulation, trauma, medication known to cause pericarditis, allergy, sternotomy history, recent acute coronary syndrome, troponin I elevation $(>0.045 \mu \mathrm{g} / \mathrm{L})$, thrombocytosis $(>400 \mathrm{G} / \mathrm{L})$, high serum creatinine levels $(>115 \mu \mathrm{mol} / \mathrm{L})$, high blood urea nitrogen level $(>7.1 \mathrm{mmol} / \mathrm{L})$ and eosinophilia $(>0.39 \mathrm{G} / \mathrm{L})$. Other variables were also retrieved in both groups including: presence of heart disease (valvular and/or ischaemic heart disease), atrial fibrillation, cardiovascular risk factors, antiplatelet therapy, heart rate, respiratory rate, high white cell count $(>9.8 \mathrm{G} / \mathrm{L})$ and high $\mathrm{C}$ reactive protein $(\mathrm{CRP})(>5 \mathrm{mg} / \mathrm{L})$.

\section{Study patients}

AIP group

Every patient with a diagnosis of AIP, and aged 16-85 years, was included. A diagnosis of AIP was retained in those having at least two of the four following criteria: typical chest pain (sharp and pleuritic, improved by sitting up and leaning forward), pericardial friction rub (a superficial scratchy or squeaking sound best heard with the diaphragm of the stethoscope over the left sternal border), ECG changes (new typical widespread ST elevation or PR depression) and new or worsening pericardial effusion. ${ }^{1}$ Idiopathic aetiology was defined as the absence of any other known aetiology including bacterial (purulent), myocardial infarction or Dressler syndrome, hyperuricaemia, neoplasm, systemic disease, intoxication and trauma. ${ }^{1}$ Patients with acute pericarditis caused by one or more of these aetiologies were excluded. The diagnosis of myopericarditis was also accepted and defined as an elevation of troponin I $(>0.045 \mu \mathrm{g} / \mathrm{L})$ in addition to the diagnosis of pericarditis. ${ }^{10}$ Microbiological investigations were not required. The following criteria were considered to rule in bacterial infection aetiology: presence of a left shift (increase of band forms) in the white cell count, positive blood culture, and history and clinical presentation compatible with a bacterial infection. If a patient had several episodes of pericarditis during the study period, we only considered the first episode.

\section{Control group}

Patients hospitalised for a DVT were chosen as a control group because DVT is not known to be associated with viral URTI or GE. ${ }^{11}$ Moreover, patients hospitalised for a DVT in internal medicine wards often had comprehensive admission notes including a complete review of systems. Finally, the number of medical records of patients with DVT was large enough to be used as a control group.

Every consecutive patient with a diagnosis of DVT, and aged 16-85 years, was included. DVT had to be diagnosed by ultrasonography performed by a radiologist. ${ }^{12}$ Patients with a history of pericarditis or myopericarditis were excluded.

\section{Statistical analysis}

Categorical variables were represented using percentages, and numerical variables were described by their median and IQRs (25th to 75th centile). Descriptive statistics were conducted for the following subgroups: pericarditis group versus control group. Differences between 
these two groups were assessed by McNemar's $\chi^{2}$ tests for categorical variables and by Snedecor and Cochran sign test for numerical variables. A two-sided $p$ value of $<0.05$ was considered to indicate statistical significance.

To evaluate the association between variables described above and pericarditis, we performed conditional logistic regressions. URTI and/or GE, heart disease, hypertension, dyslipidaemia, diabetes, smoking, obesity, antiplatelet agents, tachycardia and leucocytosis, were first included in a univariate conditional logistic regression. It was not feasible to test atrial fibrillation because of its low occurrence in the control group. All variables with $\mathrm{p}<0.2$ in the univariate model were entered in a multivariate conditional logistic regression.

All statistical analyses were performed using STATA Release V.12.0 (Stata Statistical Software: Release V.12.0, Stata Corporation, College Station, Texas, USA).

The local ethics committee (La Chaux-de-Fonds, Switzerland) approved this study.
Figure 1 Study flow chart. *Significant difference of age (>3 years) and/or gender (AIP, acute idiopathic pericarditis; DVT, deep vein thrombosis).

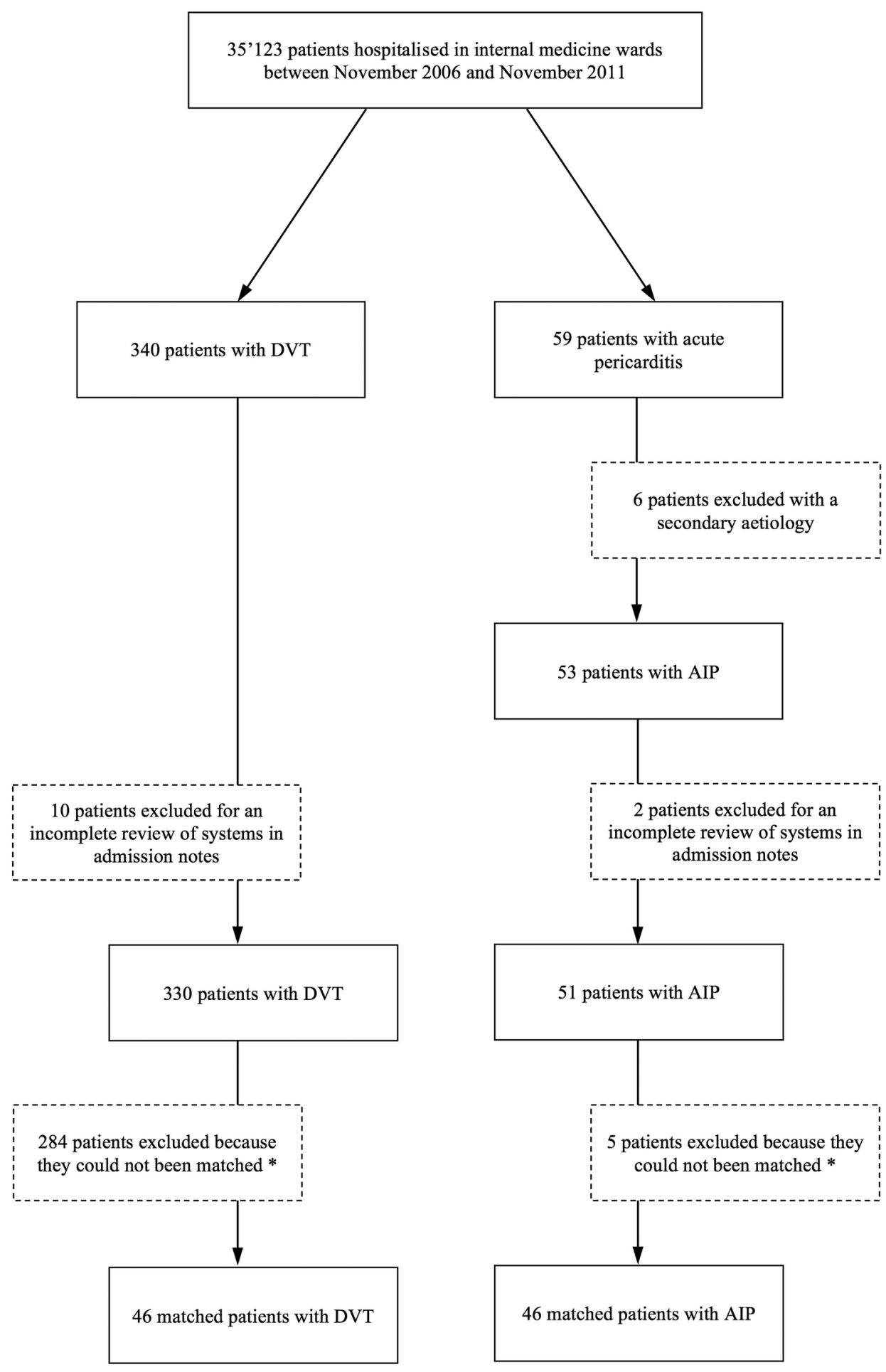


Table 1 Baseline patient characteristics

\begin{tabular}{|c|c|c|c|}
\hline & AIP group $(\mathrm{N}=46)$ & Control group $(\mathrm{N}=46)$ & p Value* \\
\hline Age, median & $57.4(42.3-66.9)$ & $58.1(42.3-68.4)$ & $0.104 \uparrow$ \\
\hline Women & 19 (41.3) & $19(41.3)$ & 1.000 \\
\hline URTI and/or GE & $18(39.1)$ & 5 (10.9) & 0.002 \\
\hline URTI & $15(32.6)$ & $1(2.2)$ & 0.001 \\
\hline GE & $3(6.5)$ & $4(8.7)$ & 0.706 \\
\hline Heart disease $\ddagger$ & $15(32.6)$ & $9(19.6)$ & 0.134 \\
\hline Atrial fibrillation & 9 (19.6) & $1(2.2)$ & 0.005 \\
\hline Hypertension & $16(34.8)$ & $16(34.8)$ & 1.000 \\
\hline Dyslipidaemia & $21(45.7)$ & $10(21.7)$ & 0.028 \\
\hline Diabetes & 9 (19.6) & $6(13.0)$ & 0.366 \\
\hline Smoking & $30(66.7)$ & $25(56.8)$ & 0.346 \\
\hline Obesity & $8(25.0)$ & 9 (19.6) & 0.480 \\
\hline Antiplatelet therapy & $10(21.7)$ & $8(17.4)$ & 0.527 \\
\hline Tachycardia & $6(13.0)$ & $13(30.2)$ & 0.090 \\
\hline Tachypnoea & $12(36.4)$ & $13(39.4)$ & 0.414 \\
\hline High WCC & $20(44.4)$ & $23(51.1)$ & 0.564 \\
\hline High CRP & $22(64.7)$ & $18(64.3)$ & 0.527 \\
\hline \multicolumn{4}{|c|}{$\begin{array}{l}\text { Categorical data are presented as number (\%) and numerical data as median (IQR). } \\
\text { *McNemar's } \chi^{2} \text { test. } \\
\text { †Snedecor and Cochran sign test. } \\
\text { †Defined as valvular and/or ischaemic heart disease. } \\
\text { AIP, acute idiopathic pericarditis; antiplatelet therapy, aspirin and/or clopidogrel; high CRP, C reactive protein }>5 \mathrm{mg} / \mathrm{L} \text {; GE, gastroenteritis; } \\
\text { obesity, body mass index } \geq 30 \mathrm{~kg} / \mathrm{m}^{2} ; \text { tachycardia, heart rate }>100 \mathrm{bpm} \text {; tachypnoea, respiratory rate }>20 / \mathrm{min} \text {; URTI, upper respiratory tract } \\
\text { infection; high WCC, white cell count }>9.8 \mathrm{G} / \mathrm{L} \text {. }\end{array}$} \\
\hline
\end{tabular}

\section{RESULTS}

There were 59 patients hospitalised with AIP in internal medicine wards between November 2006 and November 2011 in Neuchâtelois Hospital, of whom 46 were retained to be matched. At the same period of time, 340 patients were admitted for a DVT, of whom 46 could be matched (figure 1).

There were 19 (41.3\%) women in each group. Median of age was nearly similar in both groups (57.4 years old in AIP group vs 58.1 years old in control group, $\mathrm{p}=0.104)$. Patients with AIP were more likely to have atrial fibrillation and dyslipidaemia (table 1). Compared to patients with DVT, patients with AIP had more often experienced an episode of URTI or GE in the month preceding diagnosis $(18(39.1 \%)$ vs $5(10.9 \%), p=0.001$, table 1).

With three exceptions, all patients with AIP had a typical chest pain $(95.6 \%), 18(39.1 \%)$ had a pericardial effusion, 15 (34.1\%) had typical ECG changes, 1 (2.2\%) had a pericardial friction rub, $12(27.3 \%)$ had elevated troponin I and $22(64.7 \%)$ had high CRP (figure 2). Patients with elevated troponin I had a history of recent URTI or GE in $6(50 \%)$ cases. In patients with a pericardial effusion, $16(88.9 \%)$ had a mild or moderate effusion ( $\leq 20 \mathrm{~mm}$ at end-diastole on echocardiography) and $2(1.1 \%)$ had a severe effusion with tamponade. A history of recent URTI or GE was present in 5 $(27.8 \%)$ patients with a pericardial effusion.
Figure 2 Clinical findings in the acute idiopathic pericarditis group (GE, gastroenteritis; URTI, upper respiratory tract infection).

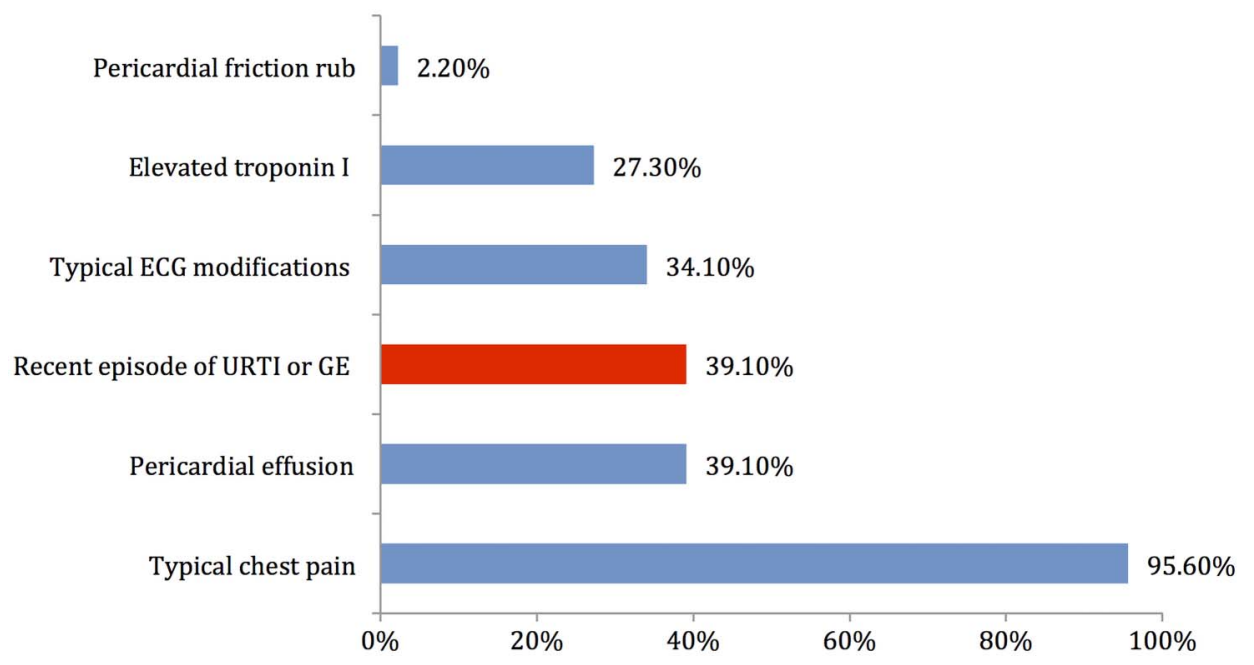


Table 2 Clinical correlates of acute idiopathic pericarditis

\begin{tabular}{|c|c|c|c|c|}
\hline & \multicolumn{2}{|l|}{ Univariate regression } & \multicolumn{2}{|l|}{ Multivariate regression } \\
\hline & OR (95\% Cl) & p Value & OR (95\% Cl) & p Value \\
\hline URTI or GE & $14.00(1.84$ to 106.46$)$ & 0.011 & 37.18 (1.91 to 724.99$)$ & 0.017 \\
\hline Heart disease $^{*}$ & $2.20(0.76$ to 6.33$)$ & 0.144 & $2.48(0.63$ to 9.80$)$ & 0.195 \\
\hline Hypertension & $1.00(0.35$ to 2.85$)$ & 1.000 & & \\
\hline Dyslipidaemia & 2.57 (1.07 to 6.16$)$ & 0.034 & $2.46(0.59$ to 10.31$)$ & 0.218 \\
\hline Diabetes & $1.75(0.51$ to 5.98$)$ & 0.372 & & \\
\hline Smoking & $1.83(0.68$ to 5.00$)$ & 0.350 & & \\
\hline Obesity & $1.67(0.40$ to 6.97$)$ & 0.484 & & \\
\hline Antiplatelet therapy & $1.50(0.42$ to 5.32$)$ & 0.530 & & \\
\hline Tachycardia & $0.42(0.15$ to 1.18$)$ & 0.100 & 0.45 (0.89 to 2.34$)$ & 0.345 \\
\hline High WCC & $0.80(0.37$ to 1.71$)$ & 0.565 & & \\
\hline
\end{tabular}

Clinical correlates with $p<0.2$ underwent multivariate analysis.

${ }^{*}$ Defined as valvular and/or ischaemic heart disease.

Antiplatelet therapy, aspirin and/or clopidogrel; GE, gastroenteritis; obesity, body mass index $\geq 30 \mathrm{~kg} / \mathrm{m}^{2}$; tachycardia, heart rate $>100 \mathrm{bpm}$;

URTI, upper respiratory tract infection; High WCC, white cell count $>9.8 \mathrm{G} / \mathrm{L}$.

In the univariate model, two variables were associated with AIP: URTI or GE in the month preceding diagnosis $(\mathrm{OR}=14.00,95 \%$ CI 1.84 to $106.46, \mathrm{p}=0.011)$ and dyslipidaemia $(\mathrm{OR}=2.57,95 \%$ CI 1.07 to $6.16, \mathrm{p}=0.034)$. In the multivariate model, one variable was independently associated with AIP: URTI or GE in the month preceding diagnosis $(\mathrm{OR}=37.18,95 \%$ CI 1.91 to $724.98, \mathrm{p}=0.017)$ (table 2).

\section{DISCUSSION}

In this retrospective case-control study, a recent (last 1-month) episode of URTI or GE was independently associated with AIP. It is important to mention that this association was mainly driven by URTI episodes. Overall, a preceding viral illness was found in 39\% of cases, which is similar to the frequency of ECG changes, pericardial effusion and pericardial friction rub described in different series of acute pericarditis. ${ }^{3} 6713$ To the best of our knowledge, this is the first study demonstrating a strong association between a recent viral illness and AIP.

The exact pathophysiology of AIP is not yet fully understood. Original viral stimuli and/or autoimmune processes are commonly considered to be the main underlying mechanisms. ${ }^{2} 714 \quad 15$ Antimyolemmal and sarcolemmal antibodies were also identified in some idiopathic cases, which gave rise to the autoimmune hypothesis. ${ }^{15}$ Overall, a systematic research of an aetiology is limited by the difficult access to pericardial tissue or fluid, variable time delay between viral infection and AIP diagnosis, and expensive investigation costs. ${ }^{3}$ Our study clearly suggests an association of AIP predominantly with respiratory infections but cannot give any clue on direct or indirect viral effects. This is in line with the different types of viruses that have been identified in acute pericarditis with effusion and that mainly have a respiratory tropism such as herpesviruses 6 , adenoviruses and parvovirus B19. ${ }^{135} 1416$ In contrast, GE was not more frequent before AIP compared to the control group. GE has been more rarely described before AIP, but enteroviruses have been shown to express a tropism for the pericardium. ${ }^{17}$

No study has specifically examined the association of AIP with preceding viral symptoms. ${ }^{18}$ In 1946, Nathan and Dathe described eight cases of pericarditis with effusion following an URTI without other intrathoracic pathologies. ${ }^{19}$ Further studies reported the presence of respiratory symptoms in the baseline characteristics of patients with pericarditis. ${ }^{5}{ }^{13}$ Different textbooks and the European Society of Cardiology guidelines suggest the possibility of observing signs and symptoms of systemic infection before disease onset. ${ }^{14}{ }^{10}$ In contrast to these previous studies, we recorded the presence of both URTI as well as GE symptoms preceding AIP but also used a control group hospitalised for a different diagnosis, with the aim of avoiding a potential bias in this association.

A number of limitations of our study should be considered. First of all, it was a relatively small cohort of patients due to the low prevalence of acute pericarditis and the limited number of patients admitted for this diagnosis. Second, because of the retrospective design, the quality of patients' interviews could not be guaranteed. However, we only considered patients with a complete review of systems in the admission notes. Patients presenting with AIP may also have been questioned in a more detailed manner about preceding viral symptoms than patients presenting with DVT. Third, URTI and GE were paired together because of the limited number of patients with URTI and GE. Fourth, this study compared patients with AIP to those with DVT, rather than with patients having other causes of chest pain syndromes. It does not inform whether patients with pericarditis are more likely to have had preceding viral symptoms as compared to patients with ischaemic chest pain. Finally, we only investigated the association of AIP with viral symptoms but we had no data regarding microbiological tests or patients' outcomes.

In conclusion, this is the first study, to the best of our knowledge, showing an association between a recent 
episode of URTI or GE and a clinical diagnosis of AIP. The clinical diagnosis of AIP may be difficult in the emergency room. According to our data, about $40 \%$ of patients with AIP had URTI or GE in the month preceding diagnosis compared to $10 \%$ in control patients. These data may help to assure physicians in the diagnosis of AIP. A large prospective study comparing the association between a recent URTI and/or GE with AIP would be needed to confirm our findings.

Contributors FR, PM, CD-C and DG made substantial contributions to the study concept and design. CD-C performed the statistical analysis. FR, PM and $D G$ drafted the manuscript. All the authors were involved in interpretation of data and critical revision of the manuscript. DG is the guarantor.

Funding This research received no specific grant from any funding agency in the public, commercial or not-for-profit sectors.

Competing interests None declared.

Ethics approval The local ethics committee (La Chaux-de-Fonds, Switzerland) approved this study.

Provenance and peer review Not commissioned; externally peer reviewed.

Data sharing statement No additional data are available.

Open Access This is an Open Access article distributed in accordance with the Creative Commons Attribution Non Commercial (CC BY-NC 4.0) license, which permits others to distribute, remix, adapt, build upon this work noncommercially, and license their derivative works on different terms, provided the original work is properly cited and the use is non-commercial. See: http:// creativecommons.org/licenses/by-nc/4.0/

\section{REFERENCES}

1. Adler $\mathrm{Y}$, Charron $\mathrm{P}$, Imazio M, et al. ESC Guidelines for the diagnosis and management of pericardial diseases. Eur Heart $J$ 2015;36:2921-64.

2. Troughton RW, Asher CR, Klein AL. Pericarditis. Lancet 2004:363:717-27.

3. Permanyer-Miralda G, Sagristá-Sauleda J, Soler-Soler J. Primary acute pericardial disease: a prospective series of 231 consecutive patients. Am J Cardiol 1985;56:623-30.
4. Zayas R, Anguita M, Torres F. Incidence of specific etiology and role of methods for specific etiologic diagnosis of primary acute pericarditis. Am J Cardiol 1995;75:378-82.

5. Abu Fanne R, Banai S, Chorin U, et al. Diagnostic yield of extensive infectious panel testing in acute pericarditis. Cardiology 2011;119:134-9.

6. Imazio M, Cecchi E, Demichelis B, et al. Indicators of poor prognosis of acute pericarditis. Circulation 2007;115:2739-44.

7. Imazio M, Belli R, Brucato A, et al. Efficacy and safety of colchicine for treatment of multiple recurrences of pericarditis (CORP-2): a multicentre, double-blind, placebo-controlled, randomised trial. Lancet 2014;383:2232-7.

8. Mossad SB. Upper respiratory tract infection. Cleve Clin 2013. http:// www.clevelandclinicmeded.com/medicalpubs/diseasemanagement/ infectiousdisease/upper-respiratory-tract-infection/ (access 3 Mar 2015)

9. Hall AJ, Rosenthal M, Gregoricus N, et al. Incidence of acute gastroenteritis and role of norovirus, Georgia, USA, 2004-2005. Emerg Infect Dis 2011;17:1381-8.

10. Caforio ALP, Pankuweit S, Arbustini E, et al. Current state of knowledge on aetiology, diagnosis, management, and therapy of myocarditis: a position statement of the European Society of Cardiology Working Group on Myocardial and Pericardial Diseases. Eur Heart J 2013;34:2636-48, 2648a.

11. Rogers MAM, Levine DA, Blumberg N, et al. Triggers of hospitalization for venous thromboembolism. Circulation 2012;125:2092-9.

12. Donnelly R, Hinwood D, London NJ. ABC of arterial and venous disease. Non-invasive methods of arterial and venous assessment. BMJ 2000;320:698-701.

13. Cohen R, Cohen-Aubart F, Steg P-G. [Acute pericarditis in the modern era: a diagnostic challenge]. Ann Cardiol Angeiol (Paris) 2008;57:10-5.

14. Lorell B. Pericardial diseases. In: Braunwald E, ed. Heart disease: a textbook of cardiovascular medicine. Philadelphia: W.B. Saunders, 1997:1478-534.

15. Maisch B, Ristic AD. The classification of pericardial disease in the age of modern medicine. Curr Cardiol Rep 2002;4:13-21.

16. Fancello L, Monteil S, Popgeorgliev N, et al. Viral communities associated with human pericardial fluids in idiopathic pericarditis. PLOS ONE 2014;9: e93367.

17. Corey GR, Campbell PT, Van Trigt $P$, et al. Etiology of large pericardial effusions. Am J Med 1993;95:209-13.

18. LeWinter MM. Clinical practice. Acute pericarditis. N Engl J Med $2014 ; 371: 2410-16$

19. Nathan DA, Dathe RA. Pericarditis with effusion following infections of the upper respiratory tract. Am Heart J 1946;31:115-30.

20. Brandenburg RO, Fuster V, Guiliani ER. Cardiology: fundamentals and practice. Chicago: Year Book Medical Publishers, 1987:47-112. 